\title{
Sobre uma nova espécie Leporinus da Amazônia
}

Heraldo A. Britski (")

\section{Resumo}

Descrição de Leporinus pachycheilus, sp. n. do rio Aripuanã, um tributário do rio Madeira, Estado de Mato Grosso. Esta nova espécie é filogeneticamente relacionada com as espécies de Leporinus de boca inferior do sudeste do Brasil, incluidas por Gery (1960) no subgênero Hypomasticus.

Recentemente, examinando as coleções de peixes do Instituto Nacional de Pesquisas da Amazônia coletados no rio Aripuanã um tributário do Madeira - encontrei uma espécie de Leporinus de boca inferior diferente das demais espécies conhecidas da bacia amazônica. Os exemplares cedidos para estudo pelo Dr. W. E. Kerr, diretor do Instituto, permitiram confirmar que pertenciam a uma nova espécie.

\section{Leporinus pachycheilus, $s p . n$.}

(Fig. 1)

Localidade-tipo - Rio Aripuanã, acima da cachoe1ra de Dardanelos, Estado de Mato Grosso.

Material-tipo - Holótipo MZUSP 13074 (157mm); parátipos MZUSP 13075 a 13087 (83 a $142 \mathrm{~mm}$ ).

\section{Diagnose}

Boca inferior, lábios grossos; 4 dentes no premaxilar e 4 no dentário; 39 a 41 escamas na linha lateral; 4 e $1 / 2$ acima e 3 e $1 / 2$ abaixo da linha lateral em série transversa.
DESCRIÇÃO

Corpo alongado; perfil dorsal em curva muito suave, do focinho até a dorsal; o perfil ventral em curva mais acentuada do ístmo até as ventrais. Boca inferior. Lábios grossos (fig. 2), sobretudo lateralmente onde é muito mais largo que na porção mediana; a borda externa dos lábios é recortada, sendo assim orlado por uma série de franjas; a porção interna do lábio é recoberta por papilas na região mediana que se escasseiam em direção à região lateral; lateralmente existe uma profunda cava que abriga a porção lateral dos lá bios, quando a boca está fechada.

A narina anterior possui um tubo curto. cuja aba posterior é mais longa que a anterior. Logo atrás da narina posterior se inicia a pálpebra adiposa que cobre uma pequena porção da parte anterior da iris; a porção posterior da pálpebra adiposa é muito mais reduzida.

Possui 4 dentes em cada premaxilar e 4 em cada dentário. Os do premaxilar são incisivos longos; o da sínfise é quase simétrico e os outros 3 laterais são progressivamente mais assimétricos. Os dentes do dentário são mais assimétricos que os correspondentes do premaxilar.

As escamas são de bordo liso em número de 39 a 41 na linha lateral, sendo 40 o número mais freqüente. Entre a linha lateral e a origem da dorsal existem 4 e $1 / 2$ séries de esca-

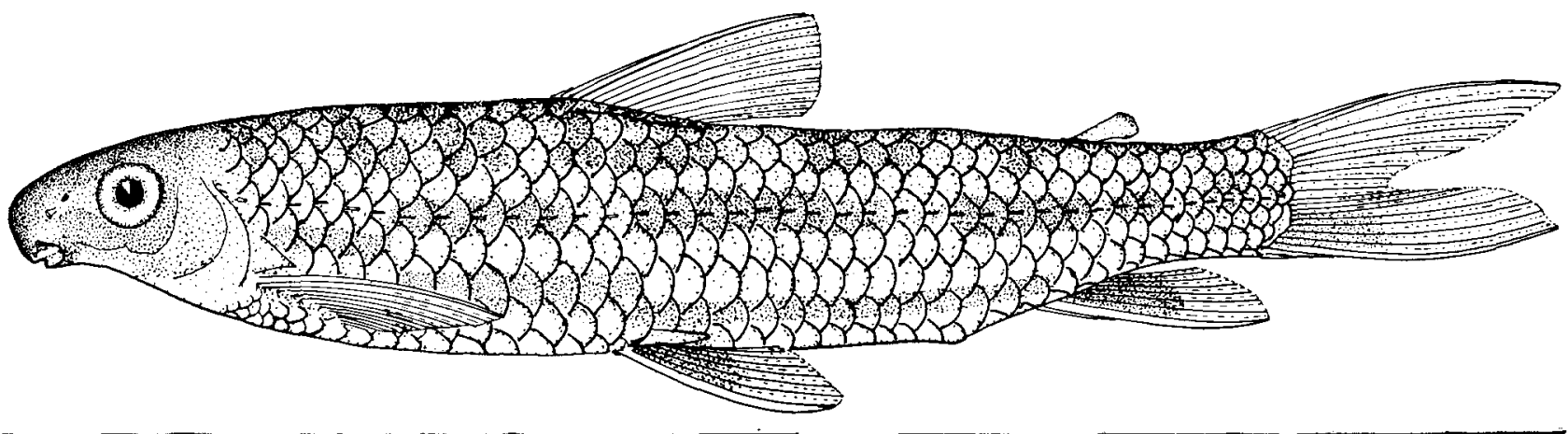

Fig. 1. Leporinus pachycheilus, sp. $\mathrm{n}$.

(') - Museu de Zoologia da USP, São Paulo. 


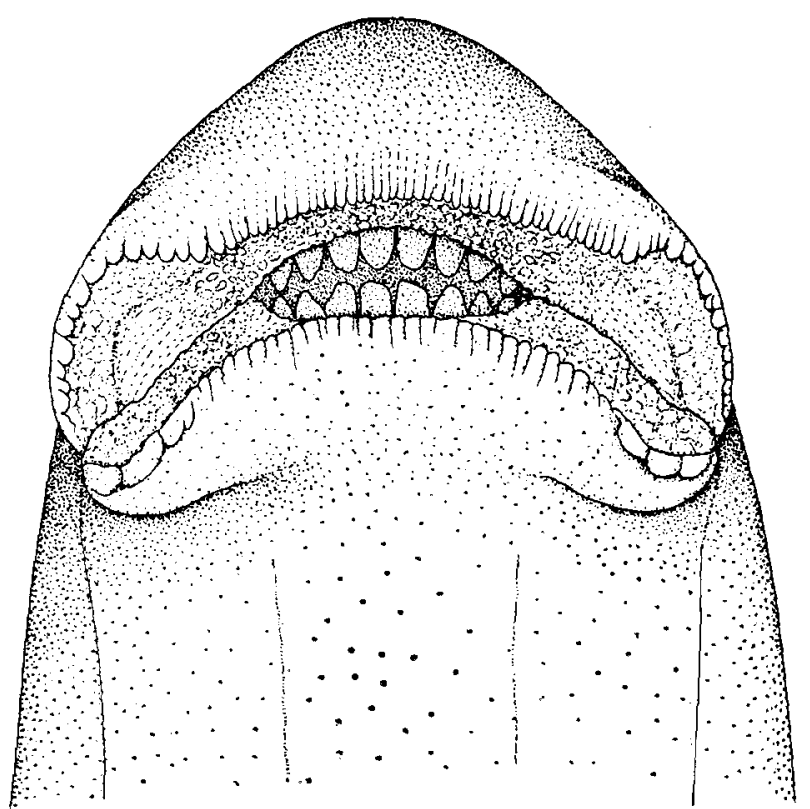

Fig. 2. Vista ventral da boca de Leporinus pachycheilus mostrando os dentes e os lábios.

mas e entre a linha lateral e a ventral 3 e $1 / 2$ a 4 séries.

As peitorais e ventrais são largas e situadas em posição inferior. A peitoral tem $i+15-17$ raios, sendo o número mais freqüente $i+16$. Ventral com $i+8$ raios; dorsal $i i i+9+i i$ e anal III $+7+i \mathrm{i}$, sendo que o primeiro raio não ramificado dessas duas últimas é muito pequeno, às vezes observado somente através de dissecção.

Os raios da dorsal, quando esta é deprimida junto ao corpo, terminam todos ao mesmo nivel. A ponta da nadadeira peitoral atirge a quarta escama à frente da base da ventral; a extremidade desta atinge a 3a., 4a. ou 5a. escama anterior ao ânus. A ventral se origina sob o $5 .^{\circ}$ ou $6 .^{\circ}$ raio da dorsal. Os primeiros raios da anal são muito longos e atingem a base dos raios caudais inferiores. Os primeiros raios da ventral e da anal são cobertos por pele espessa.

O comprimento da cabeça, a altura do corpo, a altura do pedúnculo caudal e a distância predorsal cabem no comprimento do corpo, respectivamente, 4,3 a 4,$9 ; 4$ a 4,$9 ; 9,9$ a 10,9 e 2,1 a 2,3 vezes. O diâmetro do olho, o com- primento do focinho e a largura do interorbital cabem, respectivamente, no comprimento da cabeça: 3,4 a 4,$3 ; 2,1$ a 2,4 e 2,5 a 3,1 vezes.

\section{PADRÃO DE COLORIDO DOS \\ EXEMPLARES PRESERVADOS EM ÁLCOOI $70^{\circ}$}

O padrão de colorido do corpo é inconspícuo e variado. A cor de fundo é castanhoclaro, amarelada. Nos exemplares menores o dorso apresenta manchas que parecem restos de faixas transversais que são comuns à maioria das espécies desse gênero; no flanco; sobre a linha lateral, existem três manchas muito alongadas, uma começando na porção posterior à nadadeira dorsal, outra à frente $\mathrm{da}$ adiposa e uma no fim do pedúnculo caudal; além dessas existem manchas menos conspícuas à frente da primeira e entre as duas últ!mas; ao nível da nadadeira peitoral existe uma faixa estreita, também muito pouco conspicue, parecendo ser formada de manchas alongadas. Nos exemplares maiores as manchas do dorso se tornam ainda menos definidas e ao longo do flanco existe uma faixa estreita longitudinal sobre a qual se destaca ainda as manchas originais. A metade proximal dos raios da ventral e da anal é escura; os primeiros raios, entretanto, são inteiramente esbranquiçados. A dorsal e as peitorais são hialinas. A adipo sa tem uma estreita orla escura. A cabeça é bem escura, sobretudo superiormente e na ponta do focinho; mais clara inferiormente, mas uma faixa de pigmentos castanhos circunda a parte inferior, logo atrás do lábio; outra faixa mais difusa, ao nível da parte posterior dos olhos, circunda também a parte inferior da cabeça.

Exemplares recém-fixados em formol apresentam, além das manchas escuras acima descritas, uma mancha vermelha menor que a pupila na base da $4 a$. ou 5a. até a 6a., 7a. ou 8a. escama da série longitudinal logo abaixo da linha lateral. Outra manchinha vermelha ocorre na porção lateral e superior do lábio. Aparentemente, esta mancha fica oculta quando a boca está fechada, sendo visível, pois, apenas quando ela se abre. 


\section{DISCUSSÃo}

Esta nova espécie se aproxima muito de outras espécies de Leporinus com boca inferior, tais como L. mormyrops Steindachner, $L$. garmani Borodin, L. thayeri Borodin, L. crassilabris Borodin, $L$. crassilabris breviceps Borodin e L. despaxi Puyo. Estas espécies foram reunidas por Gery (1960) sob o subgênero Hypomasticus, apesar de ter considerado tal subgênero um agrupamento artificial. O quadro abaixo, baseado em Steindachner (1875), Borodoin (1929) e Gery (1960), resume os principais caracteres dessas formas, inclusive de L. pachycheilus:

\begin{tabular}{|c|c|c|c|c|c|c|c|}
\hline & 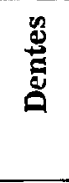 & 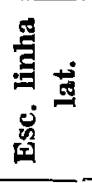 & 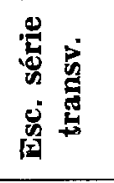 & 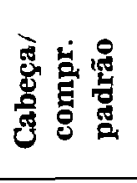 & 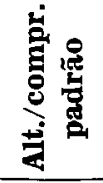 & 总 & 导飐 \\
\hline L. mormyrops & $8 / 8$ & $36-40$ & $4,5 / 3,5$ & 4,5 & 4,0 & 5,0 & 2,3 \\
\hline L. garmani & $6 / 8$ & 34 & $5 / 4$ & 4,25 & 4,75 & 4,0 & 2,75 \\
\hline L. thayeri & $8 / 8$ & 37 & $4 / 3$ & 4,5 & 4,0 & 4,5 & 2,5 \\
\hline L. crassilabris & $6 / 6$ & 37 & $4,5 / 3,5$ & 3,5 & 3,25 & 4,0 & 2,5 \\
\hline L. cr. breviceps & $6 / 6$ & $35-36$ & $4,5 / ?$ & 4,0 & 3,5 & 8,0 & 2,25 \\
\hline L. despaxi & $6 / 8$ & 33-35 & $5 / 4$ & $3,9-4,4$ & $3,3-3,7$ & $3,5-3,8$ & $2,75-3$ \\
\hline L. pachycheilus & $8 / 8$ & $39-41$ & $\begin{array}{r}4,5 \gamma^{3,5} \\
-4\end{array}$ & $4,3-4,9$ & $4,0-4,9$ & $3,4-4,3$ & $2,1-2,4$ \\
\hline
\end{tabular}

Leporinus pachycheilus, sp.n., se aproxima mais de $L$. mormyrops, $L$. thayeri e $L$. garmani não só pelo aspecto geral e forma do focinho, como também por outros caracteres. Entretanto, além das diferenças assinaladas no quadro, difere dessas espécies principalmente pelo padrão de colorido: L. mormyrops possui um padrão de faixas transversais sobre o corpo: L. garmani possui uma mancha inconspícua na base dos raios caudais medianos, porem, tanto esta espécie como $L$. thayeri não têm outras marcas sobre o corpo. L. garmani difere claramente desta nova espécie por possuir 3 dentes no premaxilar e apenas 34 escamas na linha lateral; $L$. thayeri apresenta também um número menor de escamas na linha lateral.

É preciso notar ainda que as espécies englobadas por Gery (1960) sob o subgênero Hypomasticus são da região sudeste do Brasil, exceto $L$. despaxi, da Guiana Francesa. Entretanto, segundo esse autor, L. despaxi, embora possua boca inferior, tem maiores afinidades com L. striatus. É muito provável, pois, que as demais espécies do sudeste do Brasil, sejam filogeneticamente relacionadas. L. pachycheilus, embora geograficamente separada dessas espécies, mostra claras relações com elas. Comparando-se esta espécie nova com
L. mormyrops, verificamos uma estreita semeIhança no que concerne à forma da boca, lábios, dentes, forma e posição de nadadeiras, etc. Elas diferem entre si em caracteres de pouco peso filogenético.

\section{SUMMARY}

Leporinus pachycheilus, sp. $n$. from the rio Aripuanã, a tributary of the rio Madeira, is described. This new species is related to those species of Leporinus from southeastern Brazil with an inferior mouth, included by Gery (1960) in the subgenus Hypomasticus.

\section{BIBLIOGRAFIA CITADA}

BORODIN, N. A.

1892 - Notes on some species and subspecies of the genus Leporinus Spix. Mem. Mus. Comp. Zool., 50 (3) : 269-290, pls. 1-17.

GERY, J.

1960 - Contributions a l'étude des poissons Characoïdes (7) Validité de Leporinus despaxi Puyo et du sous-genre Hypomasticus Borodin. Bull. Mus. Nat. Hist. Nat., (2)32(3) : 222-229.

STENDACHNER, F.

1875 - Die Süsswasserfische des sudöstlichen Brasilien II. Sitz. Akad. Wiss, Wien, $71: 211-245$, pls. $1-6$. 